\title{
La enseñanza-aprendizaje del español en el nivel superior: enfoques y transdisciplinariedad ${ }^{1}$
}

\section{Teaching-learning Spanish at the higher level: approaches and transdisciplinarity}

\author{
Marisela Rodríguez Peñate ${ }^{2}$ \\ ${ }^{2}$ Doctorado en Ciencias Pedagógicas; Profesora, Universidad de Ciencias Pedagógicas Enrique José \\ Varona de Cuba; mariselarp@ucpejv.edu.cu; https://orcid.org/0000-0001-7091-9264
}

Resumen: El presente artículo, recoge la experiencia de su autora durante más de 20 años en la investigación de la didáctica específica. Se propone defender la idea de que la didáctica de la lengua deberá ser necesariamente interdisciplinar, en el contexto de la educación superior pedagógica, y se apoya en los enfoques didácticos, y en la transversalidad de la lengua. Asume los nuevos enfoques de enseñanza de la lengua, en que cobra auge una perspectiva discursiva e interactiva de la significación para la interpretación del mundo natural, social y cultural, y la necesidad de asumirla centrada en los procesos de comprensión y construcción de significados y sentidos, y a partir de su uso en contextos de significación. Profundiza en la variante cubana, el enfoque cognitivo, comunicativo y sociocultural, desarrollado por la Dr.Cs. Angelina Roméu Escobar, y aborda sus aportes significativos, entre ellos, la enseñanza-aprendizaje de la lengua materna como nodo interdisciplinar, que fue el resultado de la investigación desarrollada por la autora del presente artículo como tesis en Opción al Grado Científico de Doctora en Ciencias Pedagógicas.

Palabras clave: didáctica, lengua, enfoque didáctico, nodo interdisciplinario

Abstract: This article collects the author's experience for more than 20 years in researching specific didactics. It is proposed to defend the idea that the teaching of language must necessarily be interdisciplinary, even more so in higher education. For its development, it relies firstly on the highly controversial subject of didactic approaches, and secondly, on its transversality. It assumes the new approaches to language teaching, in which a discursive and interactive perspective of significance for the interpretation of the natural, social and cultural world is booming, and the need to assume it focused on the processes of understanding and construction of meanings and meanings, and from its use in contexts of significance. Its Cuban variant has been known as a cognitive, communicative and sociocultural approach, developed by Dr.Cs. Angelina Roméu Escobar. Their significant contributions are addressed, among them, the teaching-learning of the mother tongue as an interdisciplinary node, which was developed by the author of this article as a thesis in Option to the Scientific Degree of Doctor of Pedagogical Sciences.

Key words: teaching, language, approache didactic, interdisciplinary node

\footnotetext{
1 Artículo elaborado a partir de la conferencia magistral disertada en el III Congreso: EnseñanzaAprendizaje de la lengua española en el nivel superior (2017), realizado en el Centro Universitario Regional de Azuero de la Universidad de Panamá.
} 


\section{Introducción}

José Martí, héroe nacional de Cuba y el más universal de los cubanos, nos legó, entre otras ideas, que no hay "nada mejor para agrandar y robustecer la mente que el estudio esmerado y la aplicación oportuna del lenguaje" (Martí, 1883, p.151).

Aunque la comunicación que logra el ser humano -es decir, su eficiencia al comprender y construir significados, al conocer y emplear los medios verbales o no verbales al contexto -, ha sido un signo distintivo de la persona culta -por su saber, destreza y sensibilidad-, no siempre ha existido total conciencia de la necesidad de atribuirle prioridad, por su valor en defensa de la identidad, la equidad, la integración y la plena justicia. El lenguaje nos identifica, nos iguala y nos diferencia, nos une, nos permite defender ideas y sentimientos, nos permite construirnos como seres humanos.

Acude a propósito el fragmento de una entrevista que concediera al diario Granma, el Dr.C Darío Villanueva, en visita a Cuba con motivo del 90 aniversario de la fundación de la Academia Cubana de la Lengua (ACUL)

“-¿Qué compromiso cree debe tener el individuo con su lengua?

(...) Nosotros residimos en la lengua que hablamos, pero gracias a ella podemos convivir con todos los demás y en el caso del español podemos convivir nada más y nada menos que con 500 millones de personas. Hay otros idiomas, muy respetables y muy dignos que tienen un ámbito más reducido. Todos los hispanohablantes debiéramos tener conciencia de la riqueza de nuestro idioma y hacer todo lo posible por mantenerla unida y preservarla" (Sautié, 2016, p. 5).

\section{Metodología}

Al abordar en esta ocasión la enseñanza-aprendizaje del español en el nivel superior, se presentan los principales resultados de la sistematización llevada a cabo, durante mi experiencia de más de 20 años como profesora de didáctica de la lengua y la literatura de la Universidad de Ciencias Pedagógicas "Enrique José Varona" formando profesores de Español y Literatura.

La metodología asumida reconoce la aplicación de diversos métodos de nivel teórico y empírico, entre los que resaltan el analítico-sintético, inducctivo-deductivo e histórico-lógico, así como la observación, las pruebas pedagógicas y los cuestionarios aplicados a estudiantes de pregrado y postgrado. Se estudiaron documentos 
normativos, tesis de doctorado, de maestría y de diploma. Se utilizó la modelación y el preexperimento, para la elaboración de un modelo didáctico para la enseñanza-aprendizaje de la lengua materna como nodo interdisciplinar, y para constatar la contribución del modelo propuesto. Se asume la dialéctica materialista como método general de la ciencia, combinando lo cuantitativo y cualitativo, lo externo e interno para estudiar el objeto investigado, lo general, lo particular y singular de sus manifestaciones.

\section{Resultados}

Son evidentes las dificultades en el dominio de las habilidades instrumentales de la lengua materna (hablar, escuchar, leer, escribir), que limitan a los estudiantes de los diferentes niveles de enseñanza, en su posibilidad de ser competentes para comprender, analizar y construir textos diversos, limitación que acompaña a aquellos que ingresan en los estudios universitarios pedagógicas, quienes están llamados a erradicar lo que ellos mismos poseen.

Por otra parte, al analizar los objetivos y contenidos que se proponen las asignaturas de esta disciplina para todos los niveles educativos, existe una cierta atomización e incoherencia en su tratamiento, y un énfasis en lo descriptivo y no en el uso, así como dificultades en la selección de métodos, procedimientos, formas de organización, medios de enseñanza y evaluación que activen y hagan significativo el conocimiento. Es aún insuficiente el trabajo metodológico en las instituciones educativas, para la búsqueda de soluciones conjuntas. Uno de los aspectos en el que hemos comprobado que hay desconocimiento o inadecuada aplicación es precisamente en la concepción teórica con la que sustenta su práctica el maestro de estas disciplinas, para hacerla más científica y menos empírica.

Las dificultades antes expresadas se hacen más notables, por la importancia que tiene la lengua hoy en la adquisición de los aprendizajes, en el procesamiento de la información analógica o digital y como medio de comunicación y expresión de ideas y emociones. Porque cada vez el mundo es más multicultural y plurilingüe y los grandes conflictos del siglo XXI son esencialmente de raíz cultural; por lo que enseñar a comprender -y sobre todo a comprender lo humano- es más necesario que nunca.

A lo anterior se suma que es aún insuficiente la incorporación de los resultados de las ciencias que investigan la lengua en diversas dimensiones: cognitiva, social y 
comunicativa; y que la estudian de una manera integral, al revelar el carácter interdisciplinario que permite reafirmar que el lenguaje es un fenómeno tan importante, que no puede dejársele solo a los lingüistas o a los docentes de estas materias.

En esta ocasión, nos proponemos defender la idea de que la didáctica de la lengua y la literatura en la formación de maestros deberá ser necesariamente interdisciplinar, más aún en la educación superior. Para ello nos apoyaremos esencialmente en dos cuestiones: primeramente, en el tan controvertido tema de los enfoques didácticos, y en segundo lugar, en su transversalidad.

\subsection{Enfoques en la enseñanza de la lengua}

Muchas veces no se conoce o no se admite que la evolución de las ciencias del lenguaje, junto a otras disciplinas relacionadas con su estudio, ha incidido -aunque bien sabemos que no siempre de forma directa y visible- en la pedagogía y, específicamente, en la metodología de la enseñanza de la lengua. Esto ha provocado en el ámbito escolar, desde el pasado siglo, que hayan predominado, y aún predominen, con relativa o total independencia, criterios normativos, descriptivos o productivos, para la enseñanza de la lengua y la literatura; enfoques que confluyen y perjudican la unidad del sistema educativo desde lo que pudiera aportar la enseñanza de esta disciplina.

El enfoque normativo estuvo presente en las ideas pedagógicas más antiguas, en que la memorización e imitación de los modelos clásicos imperaba y era prescriptiva la atención a la lengua escrita y correctiva a la lengua oral. Más tarde se pasa a un enfoque productivo cuya línea inductiva era dominante. En él se defendía el criterio de no dar instrucción gramatical en los primeros años de la escuela, dejando que los niños se apropiaran por sí solos de cada regla; y se priorizaba la ejercitación por ella misma, como una "gimnasia verbal".

Con el desarrollo de la lingüística como ciencia en el Siglo XX, surge la lingüística sistémica que privilegia el enfoque descriptivo, el cual centra su atención en la caracterización de la estructura de la lengua con el objetivo de describir los elementos que la conforman. Parte de la dicotomía lengua/habla propuesta por Saussure, y centra su interés en el estudio de la lengua con un fin en sí misma, divorciada de su uso en el habla. Tal enfoque tiene su expresión en una "didáctica de la lengua" que asume su proceso de enseñanza-aprendizaje de forma unidireccional, con énfasis en lo cognitivo, 
en detrimento del desarrollo de las habilidades. El generativismo conserva la dicotomía saussureana, en la dualidad que establece entre competencia y actuación, y en ocuparse solo de la primera.

Como reflejo de lo anterior, en la didáctica de la lengua, los componentes de la asignatura Español: gramática, lectura, expresión oral y expresión escrita, ortografía, eran tratados de forma aislada, y se desarrollaban paralelamente sin vincularlos de manera directa con las necesidades comunicativas de los estudiantes. Había clases para cada componente y el proceso comunicativo, que se nutre de todos, quedaba fragmentado y aislado de los aprendizajes lingüísticos.

Por ejemplo, la componente gramática, cuyo máximo nivel de análisis era la oración, sin transgredirse, pues era vedado en aquel entonces para la ciencia lingüística, no proporcionaba saberes lingüístico-comunicativos funcionales, ni enriquecía la lengua de los estudiantes para la comprensión y construcción de textos orales y escritos.

En este sentido, al ser estudiadas las estructuras lingüísticas en la oración, era imposible revelar su funcionalidad discursiva, por lo que los fenómenos de la gramática textual no podían ser abordados y la gramática oracional ni siquiera se los planteaba.

Un creciente interés de los investigadores por el habla contribuyó a transitar en la enseñanza, de una didáctica de la lengua a una didáctica del habla. Esto para vencer el principal obstáculo que ha tenido que afrontar la didáctica del español: el énfasis que ha puesto tradicionalmente en el sistema lingüístico y no en las necesidades comunicativas reales de los estudiantes.

En los nuevos enfoques de enseñanza de la lengua, cobra auge una perspectiva discursiva e interactiva de la significación para la interpretación del mundo natural, social y cultural, que plantea la necesidad de asumirla centrada en los procesos de comprensión y construcción de significados y sentidos, y a partir de su uso en contextos de significación. Se reveló la necesidad del enfoque comunicativo, con adecuaciones en Cuba, que ha llegado hasta hoy como enfoque cognitivo, comunicativo y sociocultural.

Finalmente, a partir de análisis realizados, la tendencia que se sigue para la enseñanza de la lengua y las políticas curriculares en la América Latina y del Caribe responden a los enfoques lingüístico-oracional, lingüístico-textual, gramaticalprescriptivo y funcional-comunicativo, lo que se combina con otras tendencias 
pedagógicas, y se suma el de las competencias. Lo anterior depende de las características socioculturales de cada lugar.

En la modalidad cubana se aprecia la necesidad de tener en cuenta lo sociocultural, en que también se defiende la enseñanza de diversos tipos de textos pero, a diferencia del que se sigue en otros países de América Latina, se prioriza la enseñanza de la Literatura, que en la región sigue el enfoque de recreación, concibiéndola como un medio para el desarrollo de habilidades e identificándola como un tipo de texto o género discursivo. En Cuba se enarbolan las ventajas de impartirse como una disciplina independiente del Español, aunque se debe tener en cuenta la relación entre estas.

Sobre la base de este contexto, en Cuba, los esfuerzos desplegados para encaminar la enseñanza del Español y la Literatura hacia dichas concepciones comunicativas, se concretan, a partir del año 1995, en el Programa de la Maestría en Didáctica del Español y la Literatura, fundado por la Dra. Cs. Roméu, concebido para capacitar a los profesores para dar respuesta por la vía de la investigación científica a los problemas actuales que se afrontan y ha formado seguidores de este enfoque dentro y fuera del país.

\subsection{Enfoque cognitivo, comunicativo y sociocultural}

Su inclusión en la enseñanza de las lenguas extranjeras y maternas, con las aportaciones de su aplicación, las oponencias, críticas, sugerencias, preocupaciones, reticencias, y hasta de la desinformación que ha provocado que se hayan autonombrado sus defensores quienes en la práctica no lo son, se ha permitido su permanente perfeccionamiento, para así no ser: un enfoque que niega todo lo anterior, que se erige como verdad absoluta, que no tiene en cuenta como elemento esencial lo afectivo en el análisis del discurso, que no da tratamiento específico y detenido de la gramática, la fonética, la morfología, la lexicología, la sintaxis, la ortografía y la prosodia; un enfoque que no promueve la lectura como disfrute y el enriquecimiento cultural.

Pudo establecer una relación coherente entre una teoría del lenguaje y una teoría del aprendizaje que permite explicar el papel tan importante que el lenguaje tiene en la construcción de sentido del mundo exterior y en el proceso de desarrollo cognitivo, afectivo y sociocultural del individuo.

Para Roméu, que un individuo fuera un comunicador competente suponía: 
- "Poder comprender lo que otros tratan de significar, entendida la comprensión como un acto individual, original y creador".

- "Poseer una cultura lingüística y literaria, adquirida en el proceso de análisis de diferentes textos y en el descubrimiento de los recursos lingüísticos empleados por el autor en su construcción. Dichos textos sirven de modelos constructivos en diferentes estilos (coloquial, científico-técnico y literario o artístico) y mediante su análisis el alumno no solo adquiere conocimientos lingüísticos y literarios, sino que también toma conciencia de su utilidad para la comunicación".

- “Construir textos coherentes en diferentes estilos, según las exigencias de la situación comunicativa en que se encuentre y haciendo un uso efectivo de los medios lingüísticos necesarios y estratégicos para establecer (iniciar, conducir y concluir) la comunicación de acuerdo con las características de las normas" (Roméu, 1992, p.3).

Sintetiza así el aporte principal: el tratamiento a los componentes funcionales comprensión, análisis y construcción de textos, teniendo en cuenta la dialéctica de las exigencias en los nuevos tiempos. Estas exigencias "han estado determinadas por tres factores condicionantes: el encargo social a la escuela, los problemas y necesidades de los estudiantes en lo que respecta al desarrollo de sus habilidades como comunicadores eficientes y el desarrollo alcanzado por la lingüística, la psicología, la didáctica general y otras ciencias, en las décadas finales del pasado siglo" (Roméu, 2011, p.7).

Asumir la enseñanza de la lengua desde este enfoque es asumir la unidad dialéctica entre cognición y comunicación, entre semiosis y noesis, por la importancia que se le debe conceder al lenguaje en la formación del pensamiento abstracto verbal, que le posibilita al hombre la reflexión sobre los problemas que le plantea su realidad. Abordar el estudio de la lengua en diferentes contextos de interacción, ha permitido una mejor caracterización de los discursos según el código, el orden discursivo, la función y el estilo, y establecer nuevos nexos interdisciplinarios con otras ciencias, como las jurídicas, históricas, políticas, etc.

Además, se resalta lo sociocultural por el papel del contexto en la comunicación, que es donde adquiere significación real un texto, independientemente de su tipología. Una didáctica discursiva asume como objeto no el sistema abstracto de la lengua, sino el lenguaje en uso, en elección, para apreciarlo, disfrutarlo, compartirlo, con toda su riqueza y diversidad a fin de propiciar el acercamiento al discurso como objeto complejo. 
"Es resultado del proceso de desarrollo de las nuevas concepciones lingüísticas que centran su atención en el discurso y en los procesos de comprensión y construcción de significados en diferentes contextos, a la luz de la psicología y pedagogía marxista, el enfoque Histórico-cultural y la didáctica desarrolladora, que se ha ido construyendo a partir de sus aplicaciones" (Roméu, 2007, p. 12).

Es un enfoque plural, que se nutre del avance de la ciencia, de lo mejor de nuestra tradición pedagógica, que está llamado a resolver el problema que aún hoy subsiste de la confluencia de enfoques en la escuela, que no significa que no acepte la confluencia de métodos; que insiste en hablar de lo adecuado más que de lo correcto. Pero también que haría más consciente la práctica del docente que enseña estas materias.

Se consideran como aportes más significativos los siguientes:

- $\quad$ El enfoque cognitivo, comunicativo y sociocultural ha tenido su aplicación en diferentes aspectos de la enseñanza de la lengua y la literatura, así como en el tratamiento de los procesos cognitivos, comunicativos y socioculturales que tienen lugar en la enseñanza-aprendizaje de asignaturas no filológicas.

- Se propone asumir cuatro criterios en la clasificación de los textos, en sustitución de los criterios de clasificación tradicional.

- Se remodelan programas de lengua y literatura de las carreras pedagógicas, de formación de profesores de Español-literatura y de la escuela.

- Se ha continuado profundizando en las características funcionales del discurso, en particular, del discurso científico, y la importancia de su estudio.

- $\quad$ Se ha extendido al área del español como lengua extranjera (ELE).

- $\quad$ Se plantea un modelo de clase en la asignatura Español-Literatura, en la que se propone la consideración de los componentes funcionales: comprensión, análisis y comprensión (jerarquizados o subordinados, según la clase); se considera la orientación comunicativa de los componentes didácticos, se precisa el tratamiento de las cuatro macrohabilidades comunicativas de forma integrada y el análisis del texto en sus tres dimensiones semántica, sintáctica y pragmática. 


\subsection{Un modelo didáctico para la enseñanza transdisciplinar de la lengua en la universidad}

Uno de los aportes más significativos lo constituye la declaración explícita del trabajo con lo multi-, inter- y transdisciplinar del lenguaje, lo que encuentra evidencia específica en aportes como la asunción del proceso de enseñanza-aprendizaje de la lengua materna como nodo interdisciplinar. Asimismo, en propuestas como el tratamiento integrador en el currículo de español-Literatura, desde la cultura, la identidad y la comunicación.

Si se está de acuerdo con que las diferentes ciencias han necesitado de la lengua como instrumento para la comprensión, para el análisis y para la solución de problemas (multidisciplinariedad); si además se reconoce que a través de los aportes que han hecho los estudios de la lengua se han podido alcanzar profundas aproximaciones al conocimiento del hombre, de su pensamiento, y que a su vez, de los aportes recibidos de otras ciencias, es que la lingüística ha alcanzado más certeras e integrales aproximaciones al conocimiento (interdisciplinariedad); pero más aún, si se reconoce que la lengua -y sobre todo la capacidad de cognición y comunicación en un contexto determinado que a través de ella alcanza el hombre - debe ser vista con su verdadero carácter de eje que permite lograr una integración entre las ciencias -las pedagógicas y las propias de cada disciplina que debe impartir un profesor-, habría que, al referirse a ello, hablarse de una transdisciplinariedad, como una etapa superior y más profunda de integración, como una macrodisciplina, a partir de la cual se podría construir un modelo utilizable entre las diferentes disciplinas restantes.

En Cuba se ha insistido históricamente, con la generalización de un documento denominado Programa Director de la Lengua Materna, en que todos los profesores de las diferentes asignaturas den tratamiento al aspecto lingüístico, con énfasis en la ortografía, la lectura, la oralidad y la escritura; sin embargo, los problemas han subsistido, y se ha abordado solo de manera superficial y fragmentaria.

En la práctica de la docencia, el tratamiento a lo interdisciplinar y el desarrollo de habilidades en el uso de la lengua materna, no ha sido una práctica intencional, sistemática y coherente, aunque se declaran en los Modelos de Profesional para las diferentes carreras, pues suelen abordarse los contenidos de lengua como específicos de una asignatura, y no como instrumentos indispensables para la adquisición de 
conocimientos y para la interacción comunicativa en el ámbito docente y social en general, y para la solución de sus problemas profesionales. Los profesores de estas disciplinas y carreras, si bien ven la lengua como causa de las dificultades en el aprendizaje, consideran que es un problema que deben resolver solo los profesores de Español, lo cual evidencia que no tienen conciencia de su condición como macroeje transversal del currículum y nodo interdisciplinar.

En la universidad cubana la prioridad dada a las habilidades en el uso del idioma materno han pasado desde la exigencia de una prueba de ingreso como requisito para el otorgamiento, y la ubicación en todas las carreras de las asignaturas relacionadas con la Práctica integral del idioma español, hasta que actualmente en el plan $\mathrm{E}$, se mantiene el examen y para el Curso Por Encuentros (CPE), los estudiantes deberán aprobarlo como parte de un Curso Básico, además de que solo en algunas carreras de humanidades y ciencias sociales, es considerado en el currículo base, y en otras, forma parte del propio y del optativo -electivo. Esto bajo la concepción hace algunos años de la llamada alfabetización académica que aborda uno de los problemas más recurrentes en nuestra educación superior: las dificultades de los universitarios para comprender y construir textos académicos en el contexto de las diversas materias (Carlino, 2003) (Camps, 2017).

Aprender cualquier ciencia exige la capacidad de leer y escuchar atentamente, de comunicar y compartir informaciones. La educación, lejos de asumir una posición bancaria del conocimiento, debe preparar a las personas para leer y escuchar argumentos críticamente, decidir a qué prestar atención, discernir entre ideas esenciales y profundas y las superfluas, para ser capaces de criticar sus propios argumentos, sin prejuicios ni racionalizaciones.

No se ha visto que desde una ciencia en particular y ni siquiera con el concurso de disciplinas afines, ha sido posible conocer, mucho menos dar solución, a problemas tan complejos como los relacionados con el uso de la lengua. Por ello, se investiga hoy en diversas dimensiones, a partir del desarrollo de diferentes ciencias que revelan su carácter interdisciplinario.

La enseñanza-aprendizaje de la lengua materna es un proceso mediante el cual el estudiante se apropia de conocimientos y desarrolla habilidades, capacidades y convicciones acerca de la estructura y funcionamiento de su lengua materna, sus planos y niveles, y su uso en diferentes situaciones comunicativas y contextos. 
“La enseñanza-aprendizaje de la lengua materna como nodo interdisciplinar es el proceso sistematizado e intencional en el que la lengua es asumida conscientemente por los sujetos en interacción, como macroeje transversal del currículo." (Rodríguez, 2009, p.49) Constituye un contenido cultural relevante y valioso, necesario para la vida y la convivencia, que contribuye a que los estudiantes asuman posiciones críticas y adecuadas ante los problemas profesionales y vitales en general. Por lo que todas las asignaturas tienen que contribuir a su dominio como un elemento omnipresente, que debe manifestarse en todas las actividades que de forma sistemática y coherente tengan que ver con la educación, traspasando las fronteras de los espacios académicos y de los centros formadores, pues también compete a los medios de comunicación, la prensa y toda la sociedad; pero también debe trabajarse más allá de lo fragmentario, de lo instrumental u ocasional, y ser abordado interdisciplinarmente.

Lo anterior significa que sea mediadora en la comprensión, análisis y construcción de textos, y esté presente en los procesos cognitivos, comunicativos y socioculturales que se originan en las diferentes materias de enseñanza en relación con las demás actividades formativas, lo que determina la orientación de los componentes didácticos, con una perspectiva transdisciplinar, cuestión imprescindible en la enseñanza del español en la educación superior, pues depende del sistema de trabajo metodológico diseñado, pero sobre todo de la preparación del profesor y de la concepción de su clase.

Para ilustrarlo nos referiremos al tratamiento de estas categorías didácticas:

El objetivo, componente rector del proceso de enseñanza-aprendizaje, permite revelar el alcance de la lengua en su relación con el conocimiento y la sociedad, precisar las condiciones de producción lingüística del estudiante y su incidencia en el proceso de enseñanza-aprendizaje.

En cada actividad docente o extradocente, los objetivos deberían contribuir a que el estudiante pueda: comprender las tareas a partir de la escucha y la lectura, construir por escrito y oralmente sus respuestas en sus propias estructuras conceptuales y ser capaces de ilustrarlas con ejemplos y argumentos racionales, a partir de la familiarización consciente con el vocabulario estándar y el tipo de discurso.

Dentro del contenido constituyen elementos esenciales los procesos de comprensión, análisis y construcción de textos, considerando que en todas las clases 
ocurren procesos cognitivos y comunicativos, en diferentes contextos socioculturales, cuando se trabajan otras áreas del conocimiento del mundo.

Los componentes funcionales, se orientan hacia el tratamiento de las dimensiones semántica, sintáctica y pragmática del discurso, y se establece entre ellos una relación de subordinación e interdependencia, aunque siempre se priorice uno, en relación con el objetivo que se proponga lograr en la clase. Es por esto necesario explicar su tratamiento desde el punto de vista didáctico.

La comprensión constituye el componente fundamental que está presente en el trabajo con los textos en todas las asignaturas. Implica los procesos de análisis y construcción, en tanto al comprender el alumno descubre la funcionalidad de las estructuras léxicas y gramaticales (sintaxis) en relación con el contexto (pragmática) y la significación (semántica), y reconstruye, de forma oral o escrita, el significado, a partir de sus propias apreciaciones, puntos de vista y concepción del mundo. Esto supone, que para comprender, hay que subordinar a la comprensión, el análisis de los medios lingüísticos, y valerse de los medios con los que se cuenta, para construir el significado de lo comprendido, según el contexto.

A partir del análisis de la propia acción comunicativa del profesor en el aula, estudiando su ejecución, tanto en el aspecto informativo, como en el relacional, se plantean las macrohabilidades generales para leer y escuchar que deberán desarrollarse desde una óptica interdisciplinar y que determinan los indicadores:

La habilidad para leer, en la que el interlocutor actúa como receptor. Los elementos esenciales aquí serían: La lectura u observación de gestos, situaciones, objetos, libros, imágenes, afectos; las posturas frente al texto; la posición inteligente, crítica y creadora frente a lo que se lee (atribución de significados literal, implícito y complementario, atendiendo a los tres niveles de comprensión (traducción, interpretación y extrapolación); la aplicación de estrategias de comprensión (muestreo, predicción, inferencia, autocontrol y autocorrección); la actitud voluntaria ante la lectura; las condiciones físicas; los gustos o preferencia de lectura; la corrección y fluidez (errores adiciones, omisiones, cambio, repeticiones en la pronunciación y ritmo muy rápido, semioracional o muy lento) y la expresividad (pausas, entonación de la oraciones y matices expresivos). 
La habilidad para escuchar implica una percepción exacta de lo que se dice o hace durante la situación de comunicación y asumirlo como mensaje. Los elementos son: El desarrollo de la atención y la concentración; la percepción de los estados de ánimo y sentimientos, fundamentalmente a partir de signos no verbales.

La habilidad para establecer empatía, está dada por la posibilidad de lograr un verdadero acercamiento al otro a través de las reglas de la cortesía lingüística, inherente a la relación entre docente y estudiante. Los elementos esenciales son: la personalización en la relación; la participación del otro y el acercamiento afectivo.

El análisis como componente priorizado tiene una relevancia particular en el proceso de enseñanza, por constituir el proceso de reflexión metalingüística, mediante el cual el alumno describe la funcionalidad de las estructuras, forma los conceptos, se ejercita en el empleo práctico de la lengua. Este proceso de adquisición de nuevos conocimientos por la vía del análisis reflexivo se vincula directamente con los de comprensión y construcción. Con la comprensión, porque ninguna estructura nueva para el alumno puede enseñarse al margen de su funcionalidad y de su relación con la significación del texto. Con la construcción, porque toda estructura lingüística nueva tiene que emplearse en la construcción de nuevos textos. Lo anterior es válido, tanto para los conceptos referidos al sistema, como a los referidos al discurso y a los tipos de discurso, en este caso profesionales y académicos, lo que proporciona el metalenguaje necesario para designar las estructuras y explicar sus funciones en el texto.

Este es un componente mediador entre la comprensión y la construcción de textos, por tanto le están relacionadas también las macrohabilidades: hablar y escribir (que se explicarán más adelante), las cuales se realizan mejor en tanto se han incorporado nuevos conocimientos de la lengua aprendidos en el proceso de análisis; y escuchar y leer, las cuales serán más atentas y profundas en tanto exista un mayor dominio de dichos elementos lingüísticos.

La construcción como componente priorizado, permite el desarrollo de las habilidades de comunicación oral y escrita, y su práctica descansa en el trabajo subordinado con los procesos de comprensión y análisis. Pero para poder construir, es necesario garantizar la preparación del alumno sobre qué va a escribir (semántica), cómo va a escribir (sintaxis) y en qué contexto (pragmática). Análisis y comprensión, garantizan efectividad en la construcción. 
Igualmente se parte de un enfoque procesal de la construcción textual (Domínguez G., I. 2006), a partir del análisis de la ejecución de la propia acción comunicativa del profesor, tanto en el aspecto informativo, como en el relacional, y se plantean las macrohabilidades generales para escribir y hablar que deberán desarrollarse desde una óptica interdisciplinar en la universidad:

La habilidad para escribir: Está dada por las posibilidades del hombre para transmitir mensajes escritos, de naturaleza verbal o extraverbal. Intervienen los elementos siguientes: la coherencia y claridad en la expresión de pensamientos y sentimientos (ajuste al tema, adecuación del texto al contexto, asequibilidad); la estructuración semántica y formal del texto (macroestructura semántica y formal de acuerdo con las características de la textualidad (progresión temática, coherencia, pertinencia, intertextualidad, búsqueda del texto acabado) y el empleo de métodos de desarrollo (caracterización, ejemplificación, argumentación, generalización, pormenorización, comparación, reiteración y definición); la síntesis; la elaboración de preguntas; la originalidad; la aplicación de normas ortográficas, caligráficas, morfológicas, sintácticas y textuales y de presentación).

Enseñar estrategias de lectura de cualquier texto, desarrollar el hábito de lectura, desentrañar la funcionalidad de las estructuras que se aprenden en las clases de lengua y aplicar la estrategia adecuada para una construcción oral y escrita efectiva, no es privativo de las clases de lengua. Siempre un componente estará priorizado, con respecto a los otros dos en la clase de lengua; sin embargo, en otras materias serán componentes subordinados al objetivo propio de la asignatura.

La habilidad para hablar: Está dada por las posibilidades del hombre para transmitir mensajes de naturaleza verbal o extraverbal. Los elementos esenciales coinciden con los declarados para la habilidad de escribir, pero ajustados al discurso oral, sobre todo en el cumplimiento de las normas, por lo que se agregaría el uso de recursos gestuales y el empleo de las técnicas de colocación de la voz, medio indispensable para la enseñanza.

Todo lo que sucede en el aula es susceptible de utilización para la comunicación oral, es lo más hacemos y lo menos tratado, por lo que debe haber balance entre lo oral y lo escrito. Hay que prevenir los tipos formales y corregir los informales. Destacar el 
tratamiento de la cortesía, para mantener el equilibrio social, las relaciones cordiales y la atenuación de conflictos.

El Método de enseñanza: es aquel componente que garantiza la interacción en clase con su aplicación y la solución de tareas y proyectos, por lo que se favorece la adquisición de conocimientos y el desarrollo de habilidades, capacidades y valores. La selección del método está determinada por múltiples factores, uno de ellos lo constituye la caracterización de los estudiantes y del profesor, por lo que este último debe prever alternativas ajustadas al diagnóstico. Se le concede un lugar privilegiado a la conversación productiva, heurística y problémica y al trabajo independiente reproductivo, heurístico, problémico e investigativo. Deben emplearse métodos que propicien el proceso de búsqueda de la solución de problemas empleando los conocimientos ya adquiridos y dominando la experiencia de la actividad creadora, con los que el docente estimule la reflexión personal y la asimilación de los contenidos desde la capacidad crítica del alumno y valore la novedad y originalidad de las soluciones a los diferentes problemas de la práctica y de su propia formación. Se ha detectado que falta uniformidad en los criterios y en el empleo de los métodos de enseñanza, los que suelen confundirse con los métodos de análisis propios de la ciencia.

Los procedimientos: Son aquellos componentes que, afines al tratamiento del contenido en todas las materias, complementan el método y favorecen el empleo de la lengua como nodo interdisciplinar. Entre ellos se pueden mencionar: lectura, toma de notas, solución de problemas a partir de situaciones comunicativas, preguntas y respuestas, el debate, el trabajo en equipo o independiente, los juegos didácticos, las dramatizaciones, las visitas a museos o lugares históricos, las entrevistas, los procedimientos que contengan el empleo de las tecnologías, y, entre otras, el desarrollo de diferentes técnicas de dinámica de grupo que propician sobre todo la activación intrínseca del alumno. Son estrategias discursivas implementadas en el proceso de interacción entre el profesor y los alumnos, en escenarios de aprendizaje.

Estos procedimientos favorecen el logro de un ambiente de cooperación en la clase y posibilitan, además, promover el desarrollo de habilidades, como la cultura del debate, que son esenciales para la interacción exitosa entre los miembros del grupo. 
Se deberá propiciar el intercambio entre profesores y alumnos, y entre los alumnos, para confrontar ideas, criterios, vivencias, sugerencias, para plantear dudas y proponer alternativas de solución, para fomentar habilidades investigativas.

Es imprescindible emplear adecuadamente el lenguaje no verbal (timbre, ritmo o velocidad, volumen y pausas en la voz, postura del cuerpo, expresión facial, mirada, vocalización o articulación de las palabras)

Es necesario al profesor dar tratamiento a las características de los textos según su tipología: Forma elocutiva (descriptivo, expositivo, narrativo y dialógico), código (oral, escrito, icónico, simbólico, gráfico, musical), estilo (literario, científico, coloquial, oficial y publicista), y función (Informativo, expresivo, poético y apelativo).

Hay que privilegiar el trabajo preventivo sobre el correctivo con el vocabulario técnico de cada asignatura.

$Y$ en ese intercambio permanente entre profesor y alumno, de retroalimentación mutua, de revisión y autorrevisión, de corrección y autocorrección de los procesos de comprensión y construcción del texto, el profesor debe exigir al estudiante al iniciar, desarrollar y concluir una comunicación, ser capaz de ajustarse coherentemente a las exigencias de cada situación comunicativa o contexto.

La forma de organización es aquel componente que potencia la interacción, los procesos cognitivos, comunicativos y socioculturales, la relación empática y el trabajo cooperado, con el empleo del lenguaje como mediador. Puede ser frontal, circular, semicircular, en dúos, en tríos, y otros. Se seleccionan a partir de los objetivos y los contenidos y se aplican, al abordar el contenido de cualquier materia, tanto los talleres, clases prácticas, seminarios, visitas a museos, entre otras. Guardan relación con todos los componentes del proceso, y deben contribuir al desarrollo humano.

Las formas de organización del trabajo docente se deben caracterizar por tener en cuenta el diagnóstico de los alumnos y sus diferencias, para determinar los objetivos, potenciar su independencia y participación, a partir de establecer en el marco de la actividad docente un clima psicológico adecuado.

Independientemente de la forma de organización que se adopte, se deberá tener en cuenta el protagonismo del estudiante en la exposición de su autoaprendizaje.

Los medios de enseñanza son aquellos componentes portadores del contenido, que activan el conocimiento de los estudiantes y su nivel participativo y posibilitan el 
desarrollo de la lengua como nodo interdisciplinar, en el tratamiento de los contenidos de las diferentes materias. Estos pueden ser diversos: textos académicos, científicos propiamente dichos o de divulgación científica, carteles, software, videos, etc. y forman parte de la realidad de la escuela y de su entorno.

Es necesario atender al hecho de que la información no solo llega al estudiante por la vía del profesor, sino que la complejidad en el mundo actual le exige un inmenso manejo de información computarizada y audiovisual, se sabe que a medida que aumenta su cantidad, aumenta la necesidad de buscarla, controlarla e interpretarla, lo cual sucesivamente implica cada vez más información. Y esto impone habilidades para la síntesis, para categorizarla de modo más útil, recuperarla más rápidamente, transmitirla a mayor velocidad, ordenarla y buscarla con eficiencia, además de habilidades para autorrevisar y corregir con una comprensión crítica y creadora.

Forman un sistema los medios tradicionales y novedosos: Voz (timbre, volumen, velocidad y pausas), pizarra (caligrafía, legibilidad, limpieza, organización, tratamiento al vocabulario y a la ortografía, síntesis), TIC (software y video clases, videos, música, pinturas, gráficos, mapas, etc) y otros medios (libros, diccionarios, prensa, etc.)

La evaluación es el componente que permite determinar la efectividad de la integración del resto de los componentes didácticos. Deberá ser sistemática, desarrolladora, integral e individualizadora para comprobar cómo emplea el estudiante el lenguaje como nodo interdisciplinar, lo que se manifiesta sobre todo en: el uso de la terminología; la construcción de respuestas coherentes y bien fundamentadas; el empleo de estrategias discursivas para comprender, analizar y construir textos; así como el planteamiento de problemas y la búsqueda de su solución mediante la aplicación integrada de los contenidos de las diferentes disciplinas y el empleo de métodos que garanticen un trabajo cooperado.

Es importante que exista consenso entre los docentes y entre estos y alumnos, sobre qué estudiar, y qué y cómo evaluar. Si se conoce que el objetivo central de la enseñanza-aprendizaje de la lengua materna es desarrollar la competencia cognitiva, comunicativa y sociocultural del alumno, es necesario que la evaluación se proyecte en función de comprobar si el trabajo realizado en relación con los contenidos del año se ha traducido en competencia para comprender, analizar y construir significados. Por tradición, la evaluación ha sido memorística y reproductiva; se ha encargado de medir y 
evaluar conocimientos en sí mismos, en términos de información, porque se parte de una concepción "bancaria" de la enseñanza, en la que el alumno es depositario de los conocimientos. La evaluación, sin embargo, debe medir los resultados en términos de actuación, es decir, de competencia para emplear la lengua en la conformación de las ideas y para comunicarse mejor (para comprender lo que otro significa y para construir sus propios significados de forma que los demás los comprendan).

Deben emplearse diversas vías para evaluar un mismo objetivo; además de que debe propiciarse la combinación de la autoevaluación, la coevaluación y la heteroevaluación.

La evaluación desarrolladora va dirigida, además, a contribuir a la formación, pues en ella se evalúa la calidad del contenido expuesto, y también los indicadores que forman parte del contenido del proceso de enseñanza-aprendizaje, con lo cual se favorecen cada una de las asignaturas.

Si se parte de la función diagnóstica de la evaluación, con visión interdisciplinar, ella tendrá también ese carácter integral y objetivo que se necesita, para desde ese punto proyectar todas las estrategias que garantizarán una educación para la vida.

Deben evaluarse las habilidades en el uso de la lengua materna: hablar, escribir, escuchar y leer; y debe comprobarse competencia para comprender, analizar y construir diferentes tipos de textos en dependencia del contexto.

El proceso de enseñanza-aprendizaje se caracteriza por su carácter consciente, reflexivo, problematizador, significativo y contextualizado. La organización de la metodología de trabajo en torno a ello, debe contribuir al desarrollo de las habilidades y capacidades implicadas en una actividad intelectual productiva, reflexiva y creadora en el uso de la lengua y en el aprendizaje de la literatura. El empleo de procedimientos analógicos y vivenciales, el uso del error y de la interrogación como estrategias didácticas, deben apoyar al desarrollo de las relaciones interdisciplinarias, con lo que se permitiría un mayor desarrollo de las habilidades en el uso de la lengua como medio de cognición y comunicación entre los hombres y el respeto por aquello que hace posible el esplendor humano: su cultura, su literatura, su idioma. 


\subsection{Pautas orientadoras para el maestro}

Luego de estos presupuestos proponemos unas pautas orientadoras para enseñar lengua y literatura como macroeje transversal del currículo en la escuela:

a) El profesor será un modelo lingüístico y un modelo de lector al impartir su docencia y en el diálogo orientador con alumnos, familiares y colegas. Ser todo profesor un profesor de lengua para la transmisión y adquisición de conocimientos y en el trabajo de influencia educativa. Ser el profesor de lengua y literatura, asesor para este trabajo, del resto de los profesores.

b) Transmitir respeto y motivación por el empleo adecuado de la lengua materna, medio de comunicación, y por la lectura, fuente de información y de disfrute.

c) Favorecer la investigación en aspectos lingüísticos y literarios: investigar elementos de la lengua materna con dificultades, enseñar el empleo de la superestructura esquemática y el estilo que caracteriza a todo texto diverso que revele resultados de la ciencia que se investiga, indagar sobre la vida y la obra de autores de obras de diferentes estilos y temáticas en fuentes diversas, lo que implica que tenga una buena formación en su disciplina y una formación cultural.

d) Favorecer el trabajo con la lengua materna en las actividades extradocentes, de acuerdo a las especificidades de cada contexto de actuación: familia, comunidad, trabajo metodológico, trabajo cooperado, tutoría, actividades culturales, patrióticas, deportivas: si son modelo, si facilita diferentes contextos paulatinamente más complejos con tratamiento a la diversidad textual, si se evalúan las habilidades y los componentes funcionales atendiendo a indicadores comunes referidos a la oralidad y la escritura.

e) Fortalecer la colaboración entre los docentes, puesto que el empleo adecuado de la lengua es también condición indispensable para la interdisciplinariedad con actitudes de respeto, reciprocidad y tolerancia.

f) Los componentes didácticos desde que se conciben tendrán cuenta a la lengua materna y la apreciación de la literatura, estos se definen como las categorías didácticas que en su formulación explícita revelan el tratamiento de la lengua como nodo interdisciplinar en las clases de las diferentes asignaturas del plan de estudio. 


\section{Conclusiones}

- Finalmente se puede decir que en Cuba los enfoques en la enseñanza de la lengua han estado marcados por las tendencias predominantes en el mundo, pero tienen una continuidad con la tradición pedagógica, sobre todo en esta área del conocimiento. Por otra parte, han respondido a las necesidades de la práctica, en un país que ha respetado siempre a su magisterio y que aboga por una cultura lingüística y literaria para su pueblo en defensa de esa capacidad que más nos identifica como seres humanos, y en defensa de ese idioma que es elemento troncal de nuestra identidad y herramienta imprescindible para la integración con nuestros hermanos latinoamericanos.

- Se puede constatar que la enseñanza de la lengua y la literatura se ha caracterizado mayoritariamente por la distinción de figuras relevantes, por la confluencia de enfoques, cuestión esta en la que se deberá profundizar desde los estudios históricos de la didáctica de la asignatura, así como en el hecho de no hablar del lenguaje en uso, bajo la lógica de que uno no usa lo que está dentro de uno mismo, porque no somos usuarios, porque el lenguaje no es un servicio, y no está para ser usado, por tanto el lenguaje está para ser incorporado, protegido, escuchado, entendido, para ser vivido. La asunción de la enseñanza de la lengua como nodo interdisciplinar implica que el sistema de componentes didácticos y funcionales desde cada una de las disciplinas universitarias revelan lo general, lo particular y lo singular en el tratamiento de la lengua como nodo interdisciplinar. Hacen explícito el papel que se le atribuye a la enseñanza-aprendizaje de la lengua en sus funciones noética y semiótica y la importancia de la apreciación del texto desde relaciones intertextuales, con la perspectiva de que todo profesor es un profesor de lengua.

- Para concluir, presentamos otro fragmento de la entrevista que nos permitiera iniciar esta conferencia, agregando solo un dato: la periodista, MSc Madeleine Sautié, es graduada de la mencionada maestría, con una tesis que defendió una estrategia de superación a redactores, que aplica la cortesía lingüística en el texto periodístico, asumiendo los basamentos del enfoque de referencia. El fragmento que se comparte en esta ocasión aborda la importancia de los maestros:

(...) La educación es absolutamente fundamental para el idioma, los docentes tenemos que sentirnos dueños de nuestro idioma, como el resto de los 
hablantes, pero además tenemos que sentir la enorme responsabilidad que está en nosotros para conseguir que nuestros alumnos respeten, quieran y utilicen correctamente el idioma que todos compartimos" (Sautié, 2016, p.5).

- Se hace necesario que encaminemos nuestras investigaciones a revelar aún más la identidad de nuestras naciones y su expresión en la lengua y la literatura, con estudios concertados de docentes y estudiantes y con aplicaciones consecuentes de sus resultados, con lo que formaremos profesionales no contemplativos, sino transformadores de realidades cada vez más justas, en un momento de fortaleza y expansión del idioma español, lengua que expresa un conjunto de culturas de una extraordinaria riqueza.

\section{Referencias bibliográficas}

Carlino, P. (2003). Alfabetización Académica: Un cambio necesario, algunas alternativas posibles. Universidad de los Andes. Mérida, Venezuela: Educere, 6 (20), eneromarzo, 2003. Recuperado de : http://www.redalyc.org/articulo.oa?id=35662008

Domínguez G., I. (2006). Tesis en opción al grado científico de doctora en ciencias pedagógicas, ISPEJV, La Habana.

Camps, A. (2017). 25 años de investigación en didáctica de la lengua. Conferencia dictada el 19 de enero de 2017 en la Facultad de Ciencias de Educación, Universidad Autónoma de Barcelona, en el marco de las celebraciones por el 25 aniversario de la creación de dicha Facultad.

Martí J. (1883). Prólogo a El Poema del Niágara, de Juan Antonio Pérez Bonalde. Segunda edición New York, Edición Crítica de las Obras Completas. Tomo 8, Centro de Estudios Martianos, La Habana, 2004.

Rodríguez P., M. (2009). La enseñanza de la lengua materna como nodo interdisciplinar en la formación inicial de profesores generales integrales para la secundaria básica. Tesis presentada en opción al grado científico de Doctor en Ciencias Pedagógicas. La Habana: ISPEJV.

Roméu E., A. (2011). El enfoque cognitivo, comunicativo y sociocultural de la enseñanza de la lengua: periodización y aportes. Tesis en opción al grado científico de Doctor en Ciencias. La Habana: UCPEJV. 
Roméu E., A. (2007). El enfoque cognitivo, comunicativo y sociocultural. La Habana: Editorial Pueblo y Educación.

Roméu E., A. y otros. (2003). Proyecto El enfoque cognitivo, comunicativo y sociocultural y su aplicación en la clase de lengua y literatura. La Habana: UCPEJV. Edición digitalizada.

Roméu E., A. (1992). Aplicación del enfoque comunicativo: comprensión, análisis y construcción. La Habana: IPLAC.

Sautié R., M. (2016). Los auténticos dueños del idioma son los que lo hablan. Entrevista al Dr.C Darío Villanueva. Tomado de Granma 6/10/2016: http://www.granma.cu/cultura/2016-10-06/los-autenticos-duenos-del-idiomason-los-que-lo-hablan-06-10-2016-22-10-42 